\title{
EMPLOYMENT CHANGE PATTERNS: SOME EMPIRICAL TESTS: COMMENTS
}

\section{Clayton Grant*}

The paper that I am to review is "Employment Change Patterns: Some Empirical Tests," by Lowell D. Ashby of the Regional Economics Division, Bureau of Economic Analysis, U.S. Department of Commerce. His paper was actually a reply to "Shift and Share Projections of Regional Economic Growth: An Empirical Test," by H. James Brown, in the Journal of Regional Science.

In Ashby's article, Ashby explained that he had collected data from the same sources as Brown and used the data in the same model that Brown had used but obtained opposite results. At the outset, I will admit that I did not collect the data that Brown and Ashby used and will discuss Ashby's article in terms of shift and share projection and not data collection. The firstcomment concerning the articles that I shall make is that I cannot accept the method in which Brown used the shift and sharemodel to project future regional growth. The approach used seemed to be a straight extrapolation into the future of past data relationships. The technique did not take into account the underlying causes of those relationships. If in fact Ashby and others have used the same technique for future projections, the results would be highly questionable. However, Ashby disowns any knowledge of the particular model Brown used and in fact called it Brown's version of shift and share projection.

However, the issue here seems to be whether Brown raised a relevant point and did Ashby comment on that point. Brown's major objective was to indicate by empirical test the projection capabilities of the shift and share model. But did he succeed or not? His conclusion was that "the shift and share technique is not a useful technique for regional projections" and indicated that the competitive component is:

1. not stable

2. not a useful way of classifying regional industries over time, and

3. not associated with the forces others have argued determine a region's competitive position.

There are two main criticisms of Ashby's reply to Brown:

1. his entire reply is based upon who collects data better--Brown or Ashby

and

2. if the re is a usefulness of shift and share in future projections, Ashby avoided this point which seems to be the realpoint Brown was trying to test.

The entire article by Ashby is too cumbersome and empirical to aid in answering the point raised by Brown. A well-written description and explanatory analysis based on the logical implications of shift-share procedures would seem to have been much better, with a detailed appendix for those more interested in the fine points of shift and share projection.

* The author is a graduate student in Agricultural Economics, Clemson University. 
I believe Ashby does show that Brown's assertion concerning the usefulness of classifying data by industry and analyzing it for regional purposes is not very sound; certainly, if the industrial sectors are sufficiently disaggregated, one should be able to make some kind of comparisons between the growth of a particular industry in the nation as a whole and the growth of that same industry in a given region. Butwe need to think a little more about what the competitive factor for a given industry in a particular region really means. In essence shift and share is really just an accounting procedure a system of disaggregation. The national growth factor shows the growth which would have occurred in the region if it had behaved in the same way as the nation as a whole. The composition factor shows the growth of a region due to the mix of relatively fast-growing and slow-growing industries found in that region. Thus, these two factors are based on forces exogeneous to the region. The competitive factor is a residual and its size is determined by peculiarities of the region - that is, by its comparative advantage in interregional competition. There is no reason to expect that the comparative advantage of a particular region relative to a given industry will be stable over time. Consequently, there is no reason to expect that the competitive factor will be stable overtime or even that the signs on that competitive factor will be stable. But as the comparative advantage of the region shifts, the re must be reasons to explain those shifts. Shift-share procedure cannot tell what those reasons a re but it can stimulate a search for explanations of shifts in compa rative advantage.

If Ashby's paper remains as it is now, there may be only three serious readers of the article--Ashby, Brown, and myself with everyone else reading only the first couple of pages. A well written, well-organized analysis which tackles the theoretical and practical side of shift and share projection (with an adjoining detailed appendix for proof) would have contributed much more to the literature than a concentrated attack on Brown's ability to collect data, and the use of the new data collected by Ashby in Brown's shift and share model in which Ashby didn't seem to agree with in the first place.

Ashby did cite work by Edward Miller, but the cited work is unpublished. Hopefully it will be published shortly. It would be very beneficial to know more about Miller's work. Much work needs to be performed to address the question raised by Brown, and stated in a manner in which the economist not familiar with the details of shift and share analysis can read and benefit from the article. Even thought he did not invent shift and share analysis, probably no one could do that better than Doctor Ashby, but the present paper by Ashby does little to clarify these points. 
FOOTNOTES

${ }^{1}$ Brown, H. James, "Shift and Share Projections of Regional Economic Growth: An Empirical Test. " Journal of Regional Science, Vol. 9, No. 1, 1969, pp. $1-18$. 